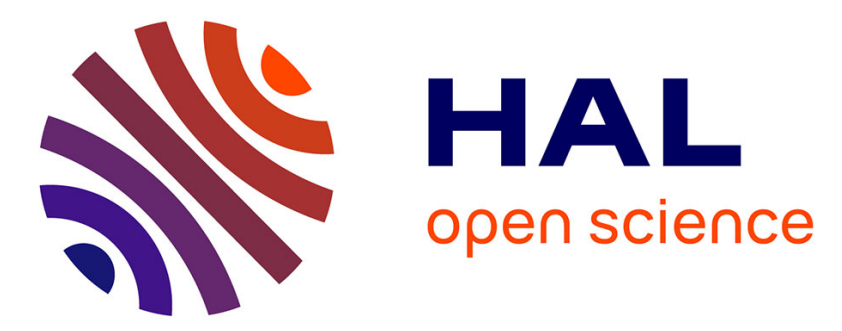

\title{
A combinaison of UV curing technology with ATL process
}

Issam Balbzioui, Basma Hasiaoui, Gerald Barbier, Gildas L'Hostis, Fabrice Laurent, Ahmad Ibrahim, Bernard Durand

\section{- To cite this version:}

Issam Balbzioui, Basma Hasiaoui, Gerald Barbier, Gildas L'Hostis, Fabrice Laurent, et al.. A combinaison of UV curing technology with ATL process. ESAFORM 2017, Apr 2017, Dublin, Ireland. $10.1063 / 1.5008008$. hal-02925275

\section{HAL Id: hal-02925275 \\ https://hal.science/hal-02925275}

Submitted on 8 Sep 2020

HAL is a multi-disciplinary open access archive for the deposit and dissemination of scientific research documents, whether they are published or not. The documents may come from teaching and research institutions in France or abroad, or from public or private research centers.
L'archive ouverte pluridisciplinaire HAL, est destinée au dépôt et à la diffusion de documents scientifiques de niveau recherche, publiés ou non, émanant des établissements d'enseignement et de recherche français ou étrangers, des laboratoires publics ou privés. 


\title{
A COMBINAISON OF UV CURING TECHNOLOGY WITH ATL PROCESS
}

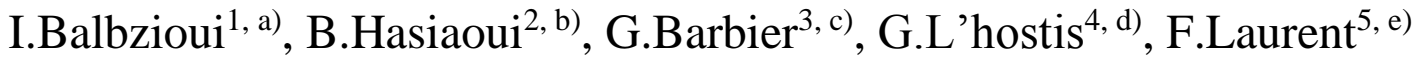 \\ A.Ibrahim ${ }^{6, f)}$ And B.Durand ${ }^{7, g}$ )
}

\author{
${ }^{12347}$ Ensisa Werner, LPMT, University Haute_Alsace, Rue Alfred Werner 68093 Mulhouse, France \\ ${ }^{6}$ LPIM, University Haute_Alsace, Rue Alfred Werner 68093 Mulhouse, France \\ ${ }^{5}$ Magyar SA, Route de Chazeuil, 21610 Fontaine-Française, France \\ a)issam.balbzioui@uha.fr \\ b)basma.hasiaoui@uha.fr \\ c) gérald.barbier@uha.fr \\ d) gildas.lhostis@uha.fr \\ e)fabrice.laurent@magyar.fr \\ f)ahmad.ibrahim@uha.fr \\ g)bernard.durand@uha.fr
}

Corresponding author: issam.balbzioui@uha.fr

gildas.lhostis@uha.fr

\begin{abstract}
In order to reduce the time and the cost of manufacturing composite, UV curing technology combined with automated tape placement process (ATL) based on reverse approach by working with a fixed head was studied in this article. First, a brief description of the developed head placement is presented. Mechanical properties are then evaluated by varying process parameters, including compaction force and tape placement speed. Finally, a parametric study is carried out to identify suitable materials and process parameters to manufacture a photo composite material with high mechanical performances. The obtained results show that UV curing is a very good alternative for thermal polymerization because of its fast cure speed due to less dependency on temperature.
\end{abstract}

\section{INTRODUCTION}

In automobile and aircraft sectors, the use of composites can reduce fuel consumption and thereby contribute to reduce the environmental impact [1]. For this reason, since 1970, there has been observed a tremendous growth in the field of automated manufacturing process and yet there seems no end to this progressing trend. Several new techniques started to appear on the composite material market. Automated Tape Laying (ATL) and Automated Fiber Placement (AFP) are the two main technologies used to automate the lay-up of thermoset and thermoplastic prepreg[2]. These processes consist of delivering prepreg (wide prepreg tape in ATL or tow in AFP) onto the adjacent surfaces to cover the entire mold. In both processes an automated machine ( 5 axis, or robot 6 axis) is used to ensure the kinematic motion of the prepreg placement system named as head placement. The current composite market placement philosophy consists of working with a fixed mold and a removable head placement. There are many advantages of this operating mode such as, the good mastery of the programing placement trajectory and the capacity to manufacture largesized parts as aircraft wings, and to keep stable the deposited prepreg. But the main problem of this approach is the cumbersome of the head placement, which limits their use to large-sized parts only and makes it difficult for small parts. In first step, consequently, we intend to work with a reverse approach, using removable mold and fixed head placement.

The second part of this work will investigate the consolidation by using UV technology (UV Curing). In spite of the proper advantages that this technology presents, like fast cure speed without decreasing the mechanical properties, 
lower cost when compared to thermal technologies, and the absence of phenomena associated to the temperature, there are still few researchers who dealt with this topic. So this field seems very promising and worthy to explore.

Finally, the obtained UV composite is performed to investigate the effect of process parameters on the mechanical properties. The obtained results show that the approach used in this paper is promising and will allow us to achieve high photo-composite material performances.

\section{REVERSE APPROACHE OF PREPREG TAPE PLACEMENT}

\section{Head Placement System}

The existing head placement systems include several functions like, road prepreg system, cut system, priming system and heating system (IR, Laser,...). In addition to these mechanical systems, there are also automatic parts, for instance the servo control of the pregreg feed speed compared to the displacement speed of the robot. All these operations make these current placement systems very cumbersome. This does not allow these systems to fabricate small parts with low curvature radius, and a preform operation has to be done after the prepreg placement on a plane. In order to overcome these convenient, in this paper we propose to work with a fixed head, having a specific geometry for the compacting area. This choice makes the accessibility of the feed roller easier for all mold surface types (plane, concave or convex; with a low or high curvature radius). So the mold is removable and holds by a 6-axis robot. The advantage of this approach is that it can be adapted to the fabrication of parts of small or large dimensions, and make our process suitable to all sectors (automotive, aerospace....), contrary to the existing ones which are limited to large parts and specific sectors like aerospace (aircraft fuselage, wings..) or renewable energy (wind turbine...).

(a)

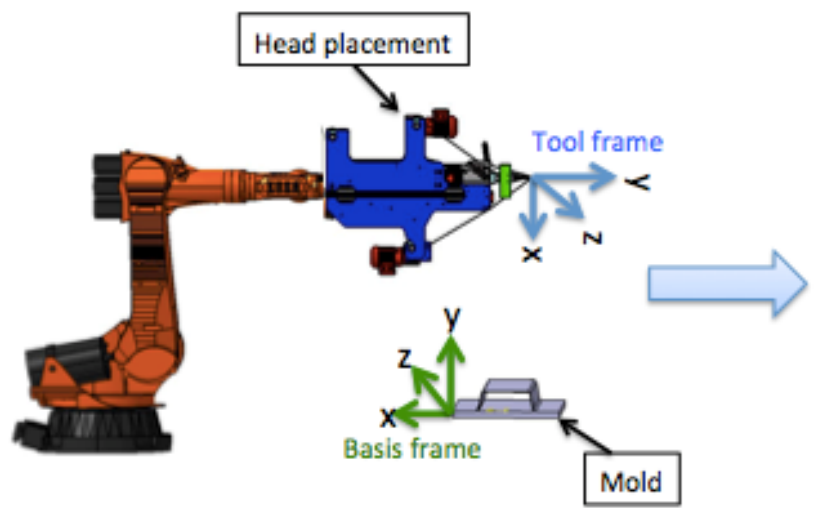

(b)

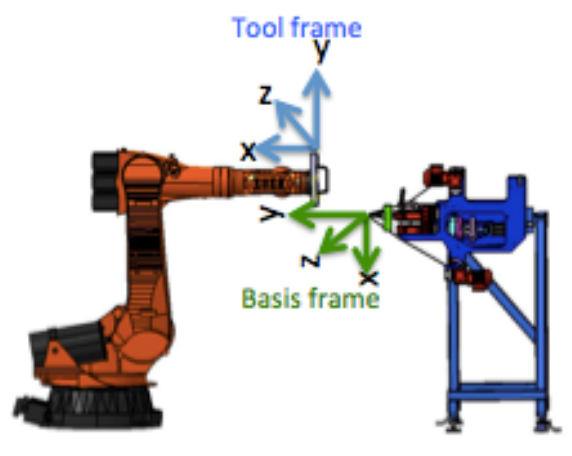

FIGURE 1: Head placement system. (a) existing approach, (b) proposed approach

Figure 1 shows the difference between the existing approach (a), and the approach proposed in this paper (b). This inverse approach requires a different programming for the robot, in particular linked to the basis and tool frame definitions. However, it is a known operating mode, which already exists in all current robot softs (mode similar to the seal deposit process for example).

The presented head placement (figure 1b), includes:

- Cutting system

- Priming system, which is ensured by the motor of a conditioning system for the prepreg protective film.

- $3 \mathrm{D}$ force sensor, to measure the force variation in the three directions. To keep a constant pressure during the process whatever the geometry, the head is mounted on a horizontal slideway, and the compaction is ensured by a pneumatic cylinder, which also plays the role of shock absorber. The force sensor is independently managed and operated, to simplify the functioning system.

- Tension control system of the prepreg. 


\section{UV Curing}

After having deposit prepreg tapes on the mold, a step of consolidation is primordial to form the final part. The resulting composite quality depends strongly on the consolidation pressure. Two types of consolidation can be used namely, in-situ consolidation, which is reached in one step under the compacting roller, and autoclave consolidation, which needs two stages (i.e. compaction by roller and autoclave cycle). In-situ consolidation with traditional heating source is very hard to be achieved, and requires a decrease in the placement speed. Thereby, using UV cure technology offers many advantages as short curing period without worrying about thermal phenomenon, less pollution, and reduction of manufacturing cost compared to the conventional head curing process [3][4]. Therefore a combination of UV curing technology and Automated Tape Placement (ATL) process is implemented to manufacture a thermoset photo composite.

\section{Materials}

Apart The UV prepreg was obtained by a impregnator machine. The polymer matrix is Nuvopole Based (Mader Research company), unsaturated $70 \%$ and diluated by $30 \%$ of styrene. As photo-initiator, $2 \%$ of Bis Acyl Phosphine Oxide (BAPO) (BASF Company) complement the mixture.

The reinforcement is a UD Glass fibers (8033F/A) from Chomarat with a width of $70 \mathrm{~mm}$, and a weight of $506 \mathrm{~g} / \mathrm{m} 2$. The mass rate of resin in the prepreg is $37 \pm 2 \%$.

\section{EXPERIMENTAL METHOD}

It was necessary to start by carrying out preliminary tests to determine the optimal exposure dose to insure a good polymerization of laminate. The assembly developed in figure 2 allows measuring light dose transmittance during process.

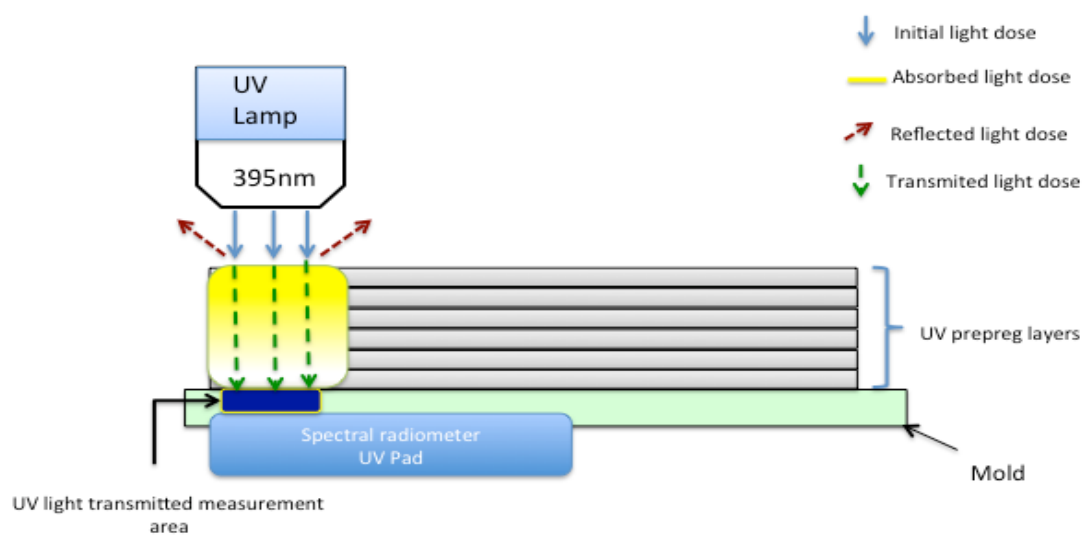

Figure 2: Transmitted UV light dose measurement

As illustrated in figure 2, the initial UV dose emitted by the lamp, is scattered on absorbed dose, reflected dose and transmitted dose. We suppose that reflected dose quantity is neglected, while the transmission $(T)$ is expressed as:

$$
T=\frac{I_{T}}{I_{0}}
$$

Where IT is the transmitted intensity (w/cm2), and I0 is initial intensity $(\mathrm{w} / \mathrm{cm} 2)$.

Knowing that:

$$
D=I_{0} \quad t
$$

Where $\mathrm{D}$ is the light dose of lamp (nm) and $\mathrm{t}$ is time (s)

At first, a no load test (without layers) is performed to determine the emitted light dose by the lamp at a given speed of the mold (which is carried by the robot). The absence of layers allows neglecting the absorbed light and considering 
that the value of the initial light dose is equal to the value displayed by the UV Pad. We named this value "reference value".

The second step, consists of depositing prepreg layers on the mold surface by the head placement system, and the process parameters used are defined using a design of experiments which will be introduced in a later paragraph.

The mold, which is carried by the robot, makes several passes under the lamp. It is considered that the substrate is completely polymerized when the dose emitted by the lamp is equal to the reference dose.

Figure 3 illustrates the evolution of the light penetration as a function the number of passes under the lamp.

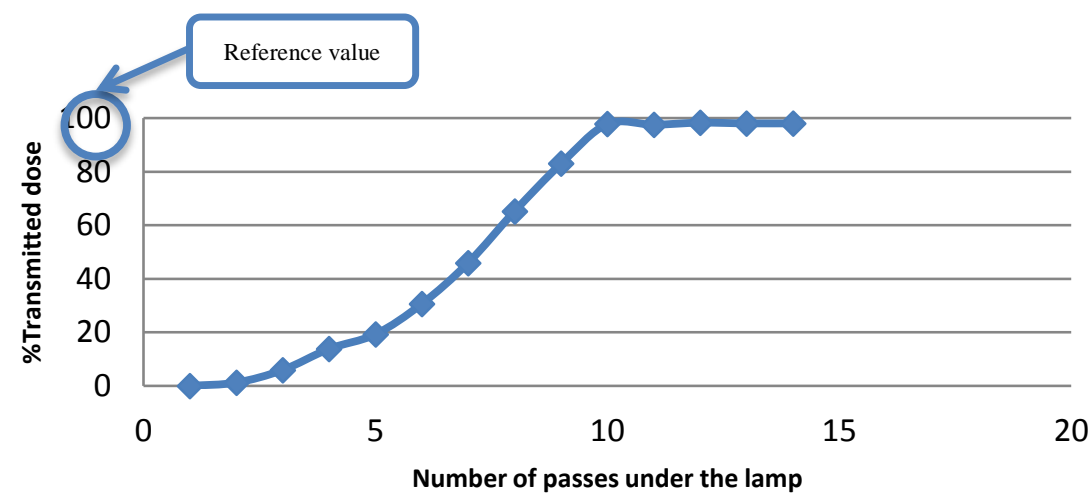

Figure 3: percentage of transmitted dose as a function of the number of passes under the UV lamp

\section{INFLUENCE OF PROCESS PARAMETRES ON MECANICAL PROPERTIES}

The objective of this part is to investigate the effect of process parameters on the mechanical properties for a 3 layers composite with a thickness of $1,7 \mathrm{~mm}$.

A full factorial design of the type nk was used is where $\mathrm{k}$ represents the number of factors $(\mathrm{k}=2)$ and $\mathrm{n}$ corresponds to the number of levels $(n=3)$.

Factors represent the process parameters namely:

- Compacting force: varied between 200 and $600 \mathrm{~N}$

- Speed placement prepreg: varied between 0,2 and $1 \mathrm{~m} / \mathrm{s}$

The mechanical properties testes performed are tensile test following NF EN ISO 527-5 standard and three-point bending following NF EN ISO 14125 standard.

Figure 4 show the influence of compacting force on the constraint and the module of tensile.

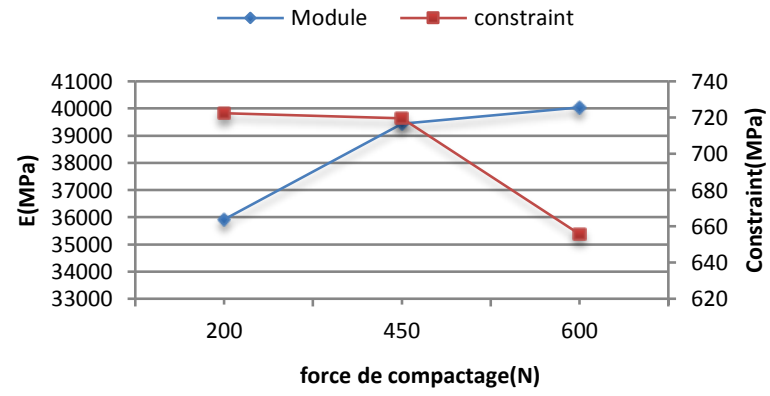

Figure 4: Influence of compacting force on mechanical properties 


\section{ACKNOWLEDGMENTS}

The authors express their grateful acknowledgement for financial support received from ADEM and Arkema. Sincere thanks also due to Ms A. Ibrahim (assistant Professor at LPIM laboratory), Mr. D. Marechal (Project engineer at Mader research company) for their valuable support.

\section{REFERENCES}

1. A.Guillaume, "Comparaison de concepts de moteur diesel en vue de leur hybridation", Ph.D. thesis, France, 2008.

2. J.E.Lindbäckand and A.Björnsson, New Automated Composite Manufacturing Process (LiU-Tryck, Linköping University, 2014).

3. D. Beziers, P. Perilleux, and Y. Grenie, Composite structures obtained by ionization curing (Radiat. Phys, Chem, 1996) vol. 48, pp. 171-177.

4. A. Dilimulati, D.Yugang, L.Dichen and L.Bingheng, A New Method for Glass-Fiber Reinforced composites Manufacturing: Automated Placement with In-situ UV Curing Fiber (Xi'an 710054, Xi' an Jiaotong University, 2011) 